\title{
ANÁLISE DA INSERÇÃO DA EDUCAÇÃO AMBIENTAL NAS ESCOLAS ESTADUAIS DA REGIÃO CENTRAL DA ÁREA DE PROTEÇÃO AMBIENTAL COSTA DOS CORAIS (AL)
}

Gildo Rafael de Almeida Santana ${ }^{1}$ José Aparecido da Silva Gama² Eliane Barbosa Santos ${ }^{3}$

Resumo: Este estudo, analisou a inserção da Educação Ambiental em duas escolas estaduais por meio da aplicação de um questionário semiestruturado que requer que os entrevistados indiquem sua percepção sobre a problemática ambiental, expondo as reais condições interdisciplinares da inserção da Educação Ambiental Formal. Os resultados indicam, que as escolas pouco conseguiram integrar seus conteúdos à prática de uma Educação Ambiental com compromisso social, crítica e emancipatória. Assim, é necessária uma educação que trabalhe a criticidade e a emancipação dos sujeitos alvo da ação principalmente entre as crianças e os jovens, para que possibilite uma mudança no panorama das desigualdades socioambientais.

Palavras-chave: Educação Ambiental Formal; Cotidiano Escolar; Pesquisa de Levantamento; Unidade de Conservação.

${ }^{1}$ Universidade Federal de Santa Maria. E-mail: gildoraphael@gmail.com

2 Instituto Federal de Alagoas. E-mail: aparecidogama1@gmail.com

${ }^{3}$ Universidade Estadual do Norte Fluminense Darcy Ribeiro. E-mail: elianebs@uenf.br

Revbea, São Paulo, V. 13, № 4: 216-227, 2018. 


\section{Introdução}

Nos últimos anos com o agravamento dos problemas ambientais, consequência das alterações provocadas na natureza, percebesse se que a Educação Ambiental (EA) vem sendo amplamente discutida como um tema importantíssimo para a melhoria da qualidade socioambiental, visto que os impactos no meio ambiente causado pela ação humana vêm sendo cada vez mais constantes. No entanto, muitas vezes esse tema estagna se na fase de discussão, pois poucas ações são efetivadas seja pelo poder público, ou pela própria sociedade. Pode-se exemplificar aqui, os resíduos sólidos que são um problema bastante visível pela população urbana, pois muitos municípios ainda não possuem um Plano de Gerenciamento de Resíduos Sólidos mesmo isso sendo uma exigência da Política Nacional de Resíduos Sólidos.

Para Capelini (2007), os resíduos são um dos mais graves problemas ambientais de causa antrópica. É importante destacar que o descarte incorreto desses resíduos, afeta o ambiente e a saúde humana e animal, diminuindo sua qualidade de vida e elevando o risco de óbito de algumas espécies. Neste sentido, mais do que uma realidade, a EA transforma-se em uma grande necessidade. Uma vez que, por meio do desenvolvimento educativo, os indivíduos possam questionar princípios, valores e refletir sobre a complexidade em que está envolvida a vida no planeta, podendo vir a se transformarem em agentes de mudança da própria realidade diante dos desafios socioambientais da atualidade. Para tanto, faz-se necessária a formação de profissionais que desenvolvam competências e estratégias mais eficazes e que possam atender as demandas ambientais, guiando-se pelos princípios fundamentados da EA crítica e emancipatória, vindo a romper com a aplicação do conhecimento fragmentado e que não leva em consideração a realidade local.

Portanto, é preciso destacar que a EA nasce como um processo educativo que leva a um saber ambiental materializado nos valores éticos e nas regras políticas de convívio social e de mercado, o que implica na questão distributiva entre benefícios e prejuízos da apropriação e do uso da natureza (SORRENTINO et al., 2005). Ou seja, se apresenta como um dos instrumentos que pretendem contribuir na formação de cidadãos críticos em relação à sua realidade. Por isso, é preciso que o educador esteja atento ao contexto social e histórico, para que possa desenvolver um programa de EA onde os envolvidos não sejam apenas coadjuvantes, mas possam estar atuando como protagonistas da transformação socioambiental (SANTANA; SANTOS, 2016(b)). No entanto, isso só será possível através de uma proposta de EA crítica e emancipatória (QUINTAS, 2009).

Devido ao seu caráter transformador, a escola tem importante papel social, e por meio da inserção da EA crítica e emancipatória em seu projeto pedagógico, pode proporcionar aos indivíduos embasamento teórico para uma reflexão sobre a sua condição real no ambiente ao qual está inserido, sendo o educador, um articulador das condições necessárias para o desenvolvimento do cidadão crítico e capaz de agir em situações práticas. Neste sentido, o 
objetivo deste trabalho é analisar através da percepção do aluno a inserção da EA nas escolas estaduais da região central da Area de Proteção Ambiental Costa dos Corais - Alagoas.

\section{Área de estudo}

A Área de Proteção Ambiental (APA) Costa dos Corais é a maior unidade de conservação federal marinha do Brasil, possui mais de 400 mil ha de área e cerca de $120 \mathrm{~km}$ de praia e mangues. Está localizada no Nordeste do Brasil, entre os municípios de Tamandaré/Pernambuco e Maceió/Alagoas (Figura 1). A presença de recifes de coral é a principal característica dessa região e, associados aos manguezais, formam o habitat de muitas espécies, inclusive de espécies ameaçadas de extinção, como o peixe-boi marinho Trichechus manatus (SANTANA; SANTOS, 2016(a)).

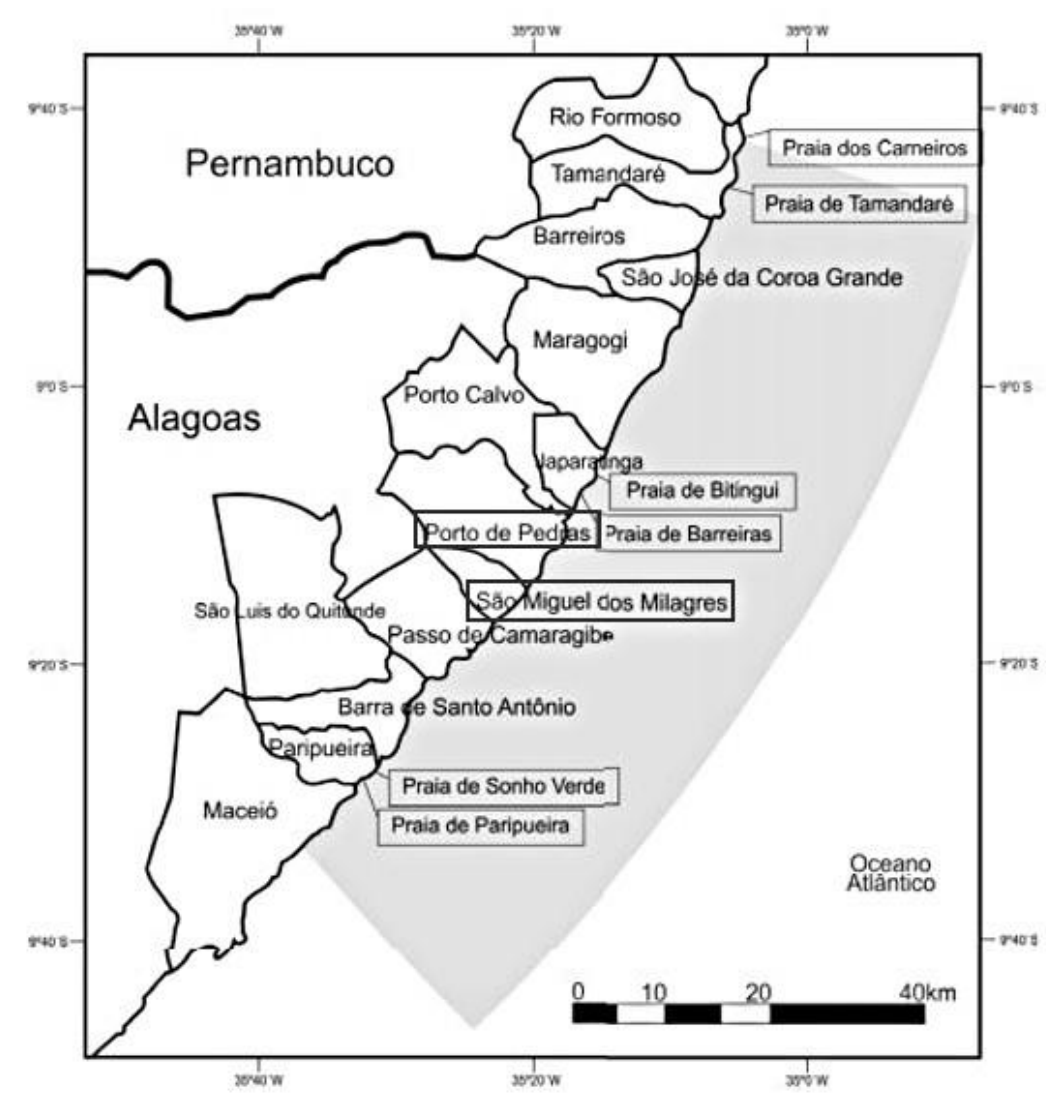

Figura 1: Área de Proteção Ambiental Costa dos Corais.

Fonte: Steiner et al., 2015.

Na região central da APA Costa dos Corais, entre Porto de Pedras-AL e São Miguel dos Milagres-AL, está localizado o recinto de reabilitação de peixes-boi marinho do Instituto Chico Mendes de Conservação da Biodiversidade (ICMBio). Esses municípios, também integram a região da Rota Ecológica, nome comumente utilizado no mercado turístico em referência a um Revbea, São Paulo, V. 13, № 4: 216-227, 2018. 
trecho do litoral norte alagoano que ingressou no cenário turístico nacional no início da década de 2000 (FRAGA, 2013).

\section{Metodologia}

O presente trabalho caracteriza se como descritivo, considerando-se que é o estudo e descrição das características levantadas e, de acordo com Gil (2002), este tipo de pesquisa tem como objetivo primordial a descrição das características de determinada população ou fenômeno, ou então, o estabelecimento de relações entre variáveis.

No que se refere ao procedimento adotado, este estudo enquadra-se no método de levantamento ou survey. Segundo Souza (2010), as pesquisas de levantamento é o tipo de pesquisa que visa determinar informações sobre práticas ou opiniões atuais de uma população específica, em geral serve para pesquisas descritivas que pretendem dizer através da população selecionada quantas pessoas têm determinados atributos, ou até mesmo explorar aspectos de uma situação, procurar explicações, entre outros. Neste estudo, foram explorados os aspectos da inserção da EA em duas unidades de ensino em Alagoas, uma localizada no município São Miguel dos Milagres (SMM) e a outra em Porto de Pedras (PP). Para a obtenção de uma amostra definida, foram entrevistados por intermédio de questionário aplicado, 347 alunos do ensino médio, 136 alunos da escola localizada em SMM e 211 da escola de PP.

O questionário contendo 11 questões, foi aplicado em novembro de 2016. Das 11 questões 6 foram relacionadas a frequência, como e em quais disciplinas são realizadas ações, trabalhos/projetos de EA. Nas demais questões, foram analisadas como essas ações influenciaram para a formação do senso crítico cidadão dos educandos e como eles veem um problema ambiental, se existe preocupação e se há interesse em ações ambientais.

As escolas alvo deste estudo, foram selecionadas por estarem inseridas dentro da maior Unidade de Conservação (UC) federal marinha do Brasil - APA Costa dos Corais - que tem como característica o uso sustentável. Esta UC deveria instigar nessas escolas o desenvolvimento de ações integradas de caráter socioambiental.

\section{Resultados e discussão}

Os resultados são apresentados no formato de gráficos de coluna com a análise comparativa entre as duas escolas analisadas neste estudo. Foram entrevistados 347 alunos, e aproximadamente, $83 \%$ e $63 \%$ afirmaram que não são desenvolvidos trabalhos/projetos de EA nas escolas de SMM e de PP respectivamente (Figura 2(a)).

Segundo a Lei $N^{\circ}$ 9.795/99, que institui a Política Nacional de Educação Ambiental (PNEA), Art. 10ำ a EA deve estar presente em todos os segmentos e níveis da educação formal de maneira que seja desenvolvida

revista brasileira educação ambiental 
como uma prática educativa integrada, contínua e permanente. No entanto, os resultados obtidos nesta pesquisa demostram que estas instituições estão caminhando na contramão da PNEA e dos Parâmetros Curriculares Nacionais (PCN's).

Quando perguntados sobre a frequência em que são desenvolvidas ações de EA, 69,57\% dos entrevistos da escola de SMM e $51,90 \%$ de PP disseram que as ações de EA na escola são desenvolvidas algumas vezes por ano como: em datas comemorativas que envolvem o meio ambiente, no dia mundial da água, dia da árvore, dia internacional da biodiversidade, entre outros (Figura 2(b)). Ou seja, apesar de alguns alunos afirmarem a existência de ações de EA (Figura 2(a)), é possível perceber que a EA não está sendo trabalhada como recomenda a Lei 9.795/99.

a)

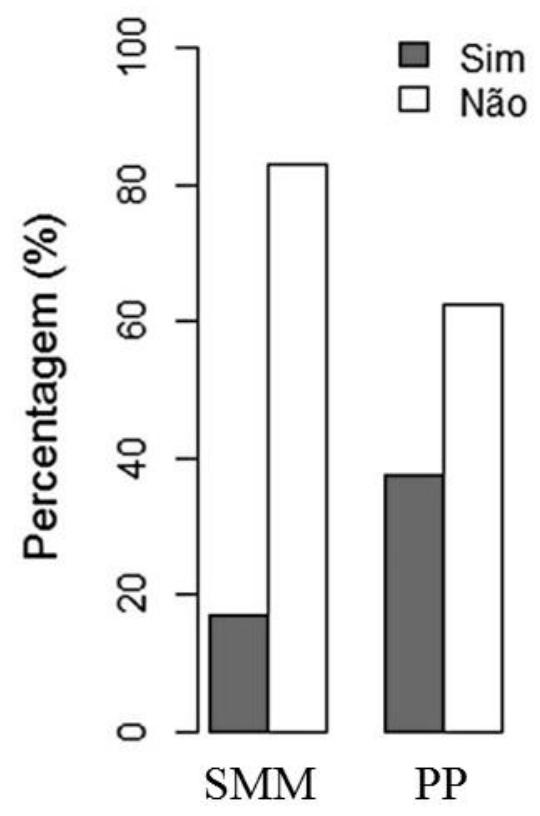

b)

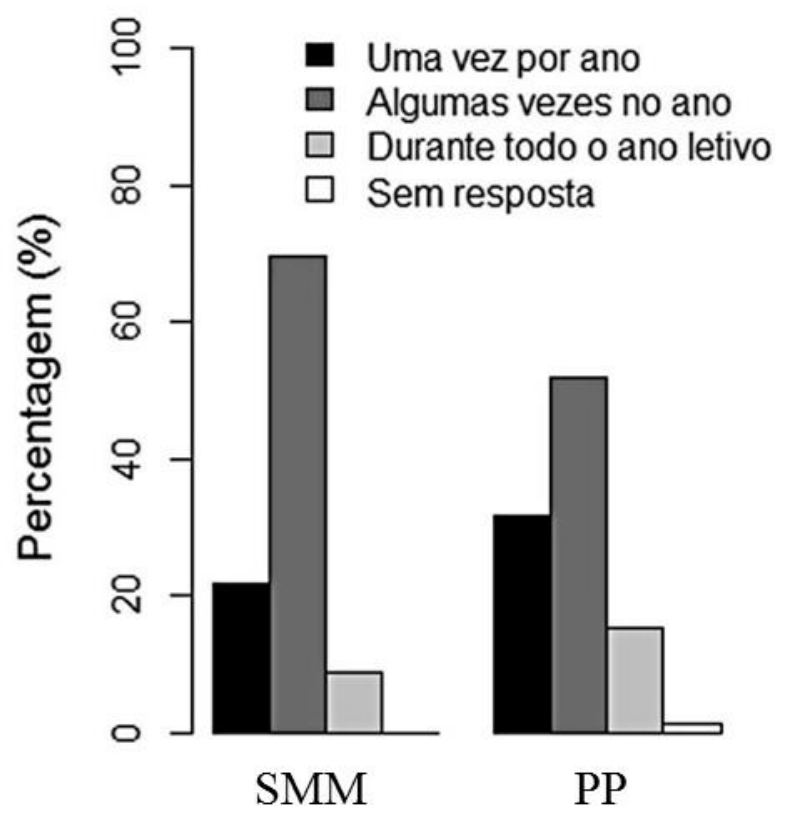

Figura 2: Respostas em percentagem da pergunta: a) Na sua escola são desenvolvidos trabalhos/projetos de Educação Ambiental? b) Com que frequência são desenvolvidas ações de Educação Ambiental?

Na Figura 3(a), é possível notar que as escolas analisadas, mostraram dados muito diferentes em relação a forma como são desenvolvidos os trabalhos/projetos de EA. Na escola de SMM, 52\% dos entrevistados, disseram que os trabalhos/projetos de EA são desenvolvidos com atividades em sala de aula e $26 \%$ disseram que estes são desenvolvidos integrando o tema as disciplinas. Enquanto que, na escola localizada em PP, $50 \%$ dos entrevistados disseram que os trabalhos/projetos são desenvolvidos através de palestras e/ou oficinas e $20 \%$ responderam que estes são desenvolvidos com atividade em sala de aula. 
Quanto as disciplinas em que os alunos estudam sobre a temática meio ambiente, na escola de SMM $43,48 \%$ dos entrevistados afirmaram que as informações sobre meio ambiente são discutidas na disciplina de Biologia e, $30,43 \%$ disseram que recebiam essas informações na disciplina de Geografia. Enquanto que na escola de PP $60 \%$ dos entrevistados disseram obter essas informações apenas na disciplina de Biologia e 32\% responderam que são informados sobre o meio ambiente através de Biologia e outras disciplinas (Figura 3(b)).

a)

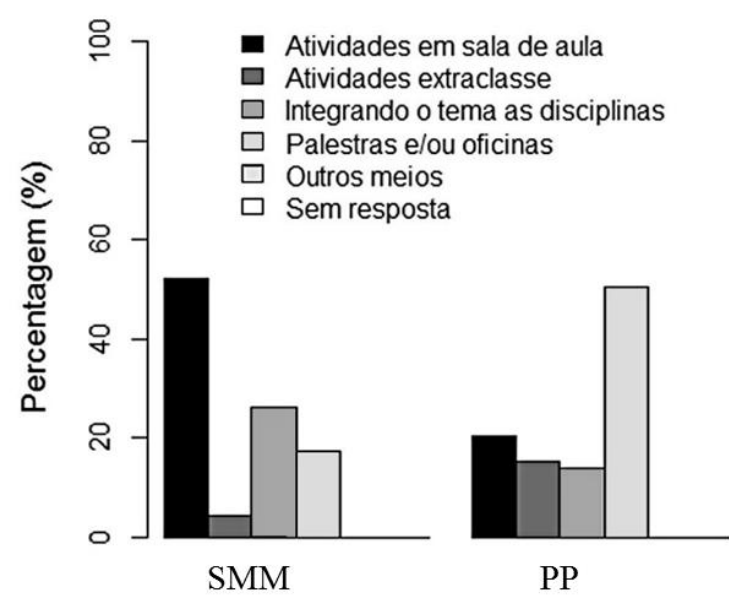

b)

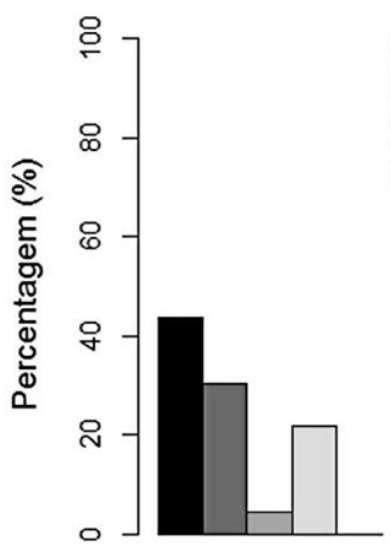

SMM
- Biologia

Geografia

Outras disciplinas

Biologia e outra(s)

Sem resposta

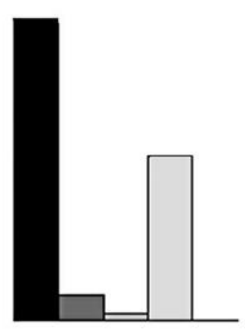

PP

Figura 3: Respostas em percentagem da pergunta: a) Na sua escola, como são desenvolvidos os trabalhos/projetos de Educação Ambiental? b) Em quais disciplinas você é informado sobre o meio ambiente?

Percebe se, que há nessas escolas uma tímida interação entre questões ambientais e as disciplinas trabalhadas em sala de aula. Todavia, os resultados mostram que ainda existe a permanência da separação da questão ambiental entre disciplinas, deixando transparecer que a responsabilidade da execução de ações de EA é da disciplina de Biologia e/ou Geografia. Contudo, segundo os PCN's, todos os componentes curriculares têm responsabilidade no ambiente escolar, pelo desenvolvimento de ações/projetos de EA independente da sua área de atuação, tendo em vista o caráter transversal da EA.

Segundo Carvalho (2008), o trabalho integrado a outras áreas tende para uma renovação da forma como nos colocamos diante o conhecimento. Desta forma quando se trabalha a questão ambiental de forma não interdisciplinar, interfere-se na forma como o sujeito poderá se portar diante de situações práticas. Pois, a interdisciplinaridade não se trata do simples cruzamento de coisas parecidas, mas sim, de construir e constituir diálogos fundamentados nas diferenças (COIMBRA, 2010). Assim, torna-se essencial o envolvimento de outras disciplinas no desenvolvimento de ações para a inserção dos temas ambientais nas escolas. 
Quando perguntado sobre os problemas ambientais da localidade, os resultados obtidos nas duas unidades de ensino foram semelhantes entre si, onde $47 \%$ dos entrevistados da escola de SMM e $46 \%$ de PP, afirmaram que 0 problema é o lixo, enquanto que 38\% (escola de SMM) e 37\% (escola de PP), disseram ser 0 desperdício de água/energia (Figura 4(a)). Esses dados, mostram que apesar deste estudo encontrar fragilidades na execução das ações de EA nessas escolas, os educandos percebem como problemas ambientais a destinação inadequada dos resíduos "lixo" e o desperdício de água/energia. Essa percepção pode ser entendida como uma contribuição da EA no desenvolvimento educativo desses alunos.

a)

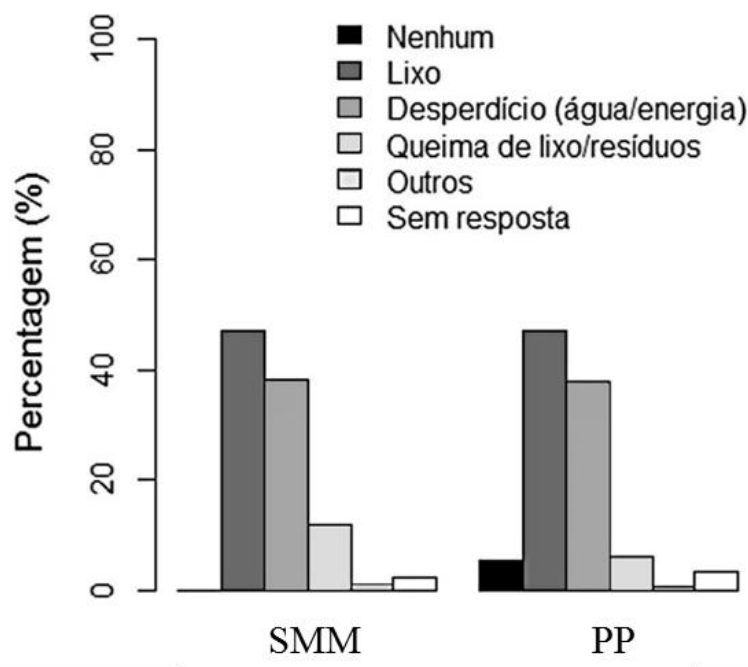

b)

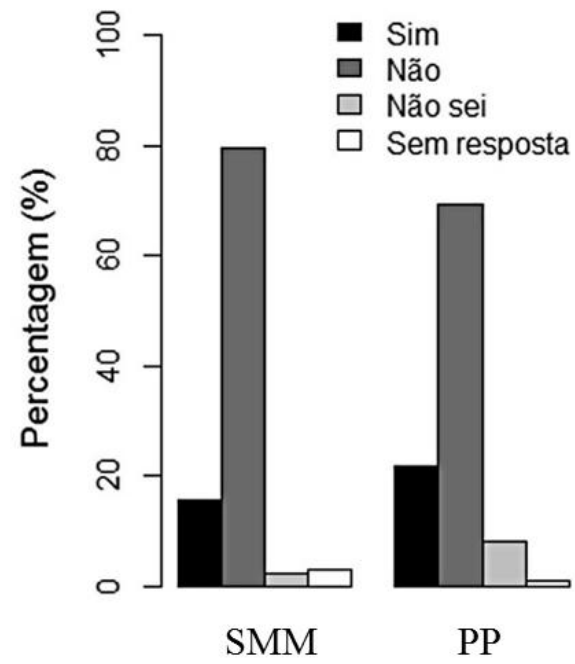

Figura 4: Respostas em percentagem da pergunta: a) Quais problemas ambientais você encontra em sua escola, em casa e em seu município? b) Na sua escola possui lixeiras para coleta seletiva?

$\mathrm{Na}$ Figura 4(b), é possível notar que $15,44 \%$ e $21,80 \%$ dos entrevistados, afirmaram haver lixeiras para coleta seletiva nas escolas de SMM e PP respectivamente. Todavia, nenhuma das escolas alvo deste estudo possui tais lixeiras, como confirmado pela maioria dos entrevistados, $79,43 \%$ (escola de SMM) e 69,19\% (escola de PP).

Quando perguntados se no município onde residem existe coleta seletiva, as respostas obtidas foram parecidas entre as escolas analisadas, onde $19,85 \%$ (escola de SMM) e 20,85\% (escola de PP) dos entrevistados afirmaram que há coleta seletiva no município. Enquanto que, 19,85\% (escola de SMM) e 28,91\% (escola de PP) não souberam responder (Figura 5(a)). Esses resultados, sugerem que alguns alunos não entendem o que é a coleta seletiva, pois até a data da realização deste estudo os municípios de Porto de Pedras e São Miguel dos Milagres não contavam com coleta seletiva, de modo que os resíduos são coletados de forma rudimentar e precária, destinados aos lixões e queimados a céu aberto. Atividade que gera sérios problemas Revbea, São Paulo, V. 13, № 4: 216-227, 2018. 
ambientais e de saúde pública, pois há contaminação do solo e do ar, elevando os riscos de problemas respiratórios e de contaminação de águas subterrâneas.

Quanto a responsabilidade pelo meio ambiente, mais de $87 \%$ do total de entrevistados nas duas unidades de ensino (Figura 5(b)), disseram que essa responsabilidade é de todos, mas há ainda os que acreditem (12,99\%) que a responsabilidade pelo meio ambiente seja do poder público municipal, eximindo-se a responsabilidade individual. No entanto, segundo o artigo 225 da Constituição Federal de 1988, todos têm direito ao meio ambiente equilibrado ecologicamente, sendo um bem de uso comum e primordial para a qualidade de vida do povo. Sendo dever da coletividade e do poder público defende-lo e preservá-lo de forma que este seja garantido para a presente e futuras gerações.

Todavia, para que isto ocorra, é indispensável que a EA seja trabalhada de forma integrada e com compromisso social. Pois, uma EA com compromisso social vai além das questões ambientais integrando-se ao campo da formação política dos indivíduos e almejando mudanças sociais e estruturais nas comunidades.

a)

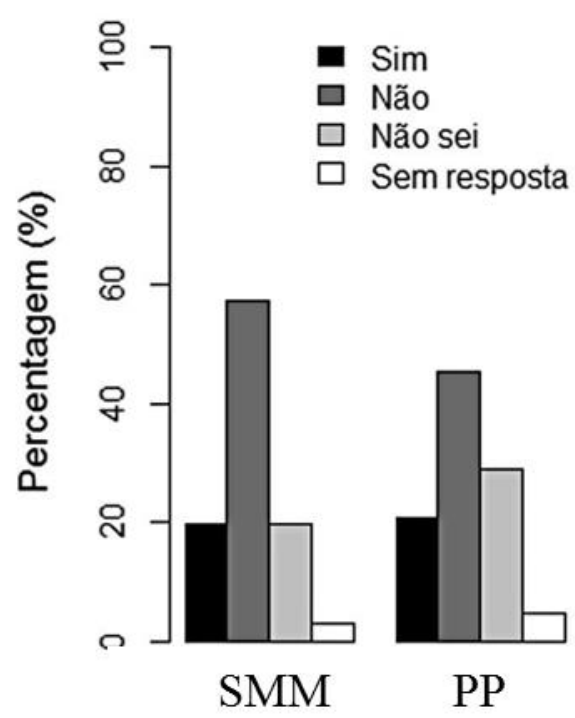

b)

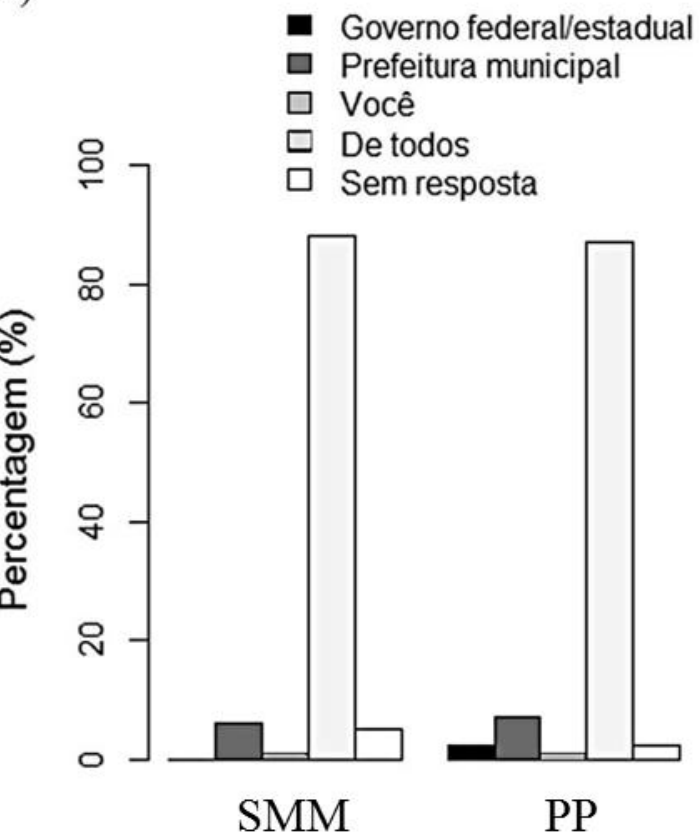

Figura 5: Respostas em percentagem da pergunta: a) No seu município há coleta seletiva dos resíduos? b) De quem é a responsabilidade pelo meio ambiente?

Com relação a preocupação em não jogar lixo na rua, mais da metade dos alunos entrevistados na escola de SMM (54,41\%), disseram que se preocupam algumas vezes em não jogar lixo na rua outros $(26,47 \%)$ 
responderam que sempre se preocupam. Enquanto que $45,97 \%$ dos entrevistados na escola de PP afirmaram que se preocupam as vezes e, $38,86 \%$ responderam que sempre se preocupam em não jogar lixo na rua (Figura 6(a)). Esses resultados sugerem que há uma preocupação com o descarte incorreto do lixo, demonstrando traços de conscientização ambiental. Essa conscientização pode ser entendida como a mudança de comportamento, tanto em atividades quanto em aspectos da vida, dos indivíduos e da sociedade em relação ao meio ambiente (BUTZKE et al., 2001).

Ao perguntar aos alunos como eles preferiam discutir problemas ambientais, na escola de SMM $41,18 \%$ dos entrevistados disseram que tem preferência por palestras e/ou vídeos e, 44,12\% afirmaram que preferem trabalhos práticos. Na de $\mathrm{PP}$, mais da metade $(54,50 \%)$ responderam que preferem palestras e/ou vídeos e 35,55\% optam por trabalhos práticos (Figura 6(b)). Neste sentido, é perceptível que ainda há uma divisão entre teoria e prática nas ações de EA nessas escolas, diferente do que deveria ser a práxis educativa, pois essa não se refere apenas as ações pedagógicas, mas também às suas intencionalidades.

a)

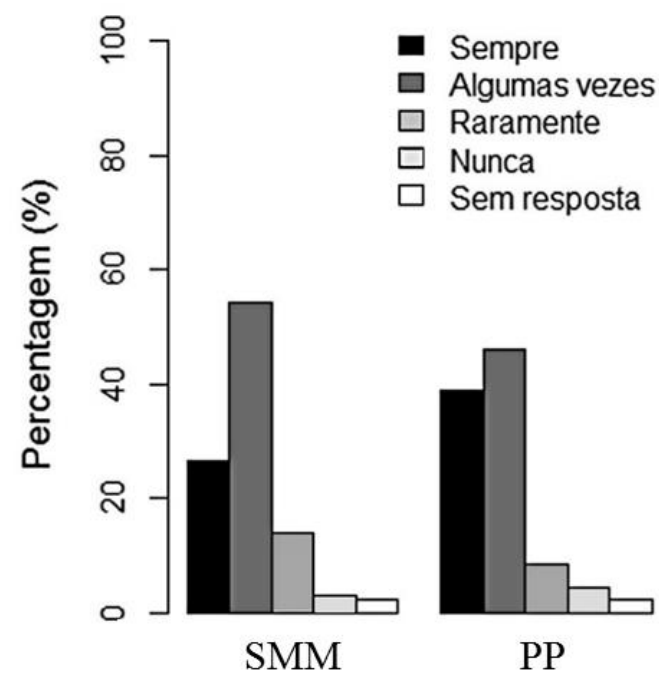

b)

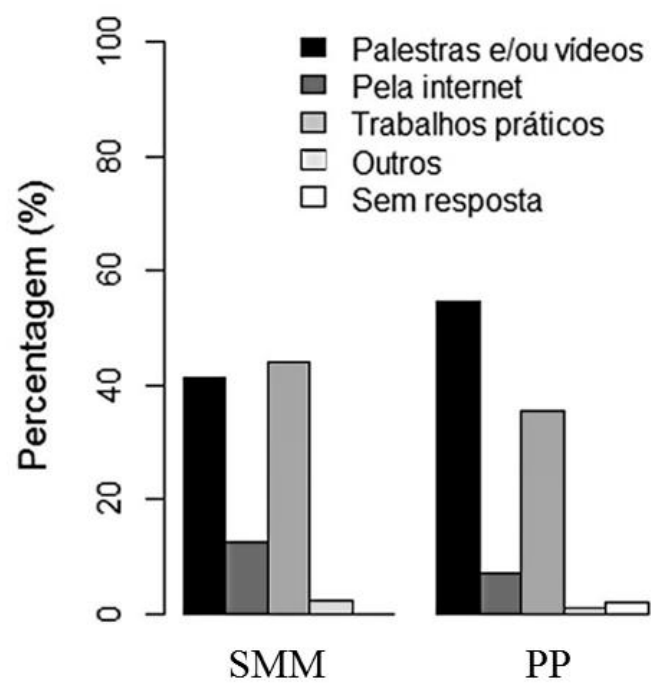

Figura 6: Respostas em percentagem da pergunta: a) Você se preocupa em não jogar lixo na rua? b) Como você prefere discutir e/ou assimilar os problemas ambientais? 


\section{Conclusão}

Os resultados obtidos demostram que os trabalhos/projetos de Educação Ambiental realizados nas escolas dos municípios São Miguel dos Milagres - $A L$ e Porto de Pedras - AL, podem não estar sendo executados de forma participativa e inclusiva, pois a maioria dos entrevistados afirmou não existir ações/projetos nessas escolas, afirmando ainda que ações/projetos são desenvolvidas algumas vezes no ano e em disciplinas específicas como Biologia e Geografia.

Todavia, apesar da visível fragilidade nas execuções dos trabalhos com temas ambientais, há um entendimento de que os resíduos e o desperdício de água são considerados graves problemas ambientais. Esse traço de conscientização ambiental se reflete no fato da maioria afirmar que a responsabilidade pelo meio ambiente é de todos, apesar de grande parte dos alunos terem afirmado que apenas algumas vezes se preocupam em não jogar lixo no chão.

Com relação às políticas públicas que deveriam propiciar ações de separação dos resíduos, tanto as escolas quanto os municípios não as proporcionam, pois não existem lixeiras para coleta seletiva, nem incentiva a reciclagem e não ocorre a destinação adequada dos resíduos. Logo, é necessário que haja uma mudança no comportamento dos cidadãos e dos gestores, sendo o investimento em políticas públicas e na Educação Ambiental condição necessário para que essa mudança ocorra.

Os resultados obtidos também sugerem que as escolas não conseguiram integrar os conteúdos das disciplinas em seus projetos ambientais a prática de uma Educação Ambiental com compromisso social. Uma vez que, não foi encontrado uma real mudança de postura dos educandos frente as questões ambientais locais.

Tendo em vista que, as escolas analisadas neste estudo, são as únicas há ofertarem o ensino médio regular na região, sua contribuição para o desenvolvimento de um ambiente de contato direto com as questões socioambientais e de troca de saberes entre educadores e educandos deve ser cuidadosamente trabalhada, para que possa servir como ambiente prático das reflexões socioambientais. Haja vista que, a presença de associações, ONG's, e instituições ligadas às ações ambientais nestes municípios, tendem a contribuir para o aumento dessas ações com o intuito de aproximar e incentivar as comunidades a exercer sua cidadania e cobrar do poder público uma minimização dos impactos ambientais negativos na região. Portanto, é indispensável que ocorra uma maior aproximação entre a sociedade civil organizada e as instituições de ensino.

revista brasileira educação ambiental 


\section{Referências}

BUTZKE, I.C. et al., Sugestão de indicadores para avaliação do desempenho das atividades educativas do sistema de gestão ambiental - SGA da Universidade Regional de Blumenau - FURB. Revista Eletrônica do Mestrado em Educação Ambiental. Vol. Esp. abr./maio/jun.-2001.

BRASIL. Constituição (1988). Art. 225. Constituição da República Federativa do Brasil. Brasília, DF: Senado Federal: Centro Gráfico, 1988. 292 p.

BRASIL. Lei $N^{\circ}$ 9.795, de 27 de abr. de 1999. Dispõe sobre a Educação Ambiental, institui a Política Nacional de Educação Ambiental e dá outras providências, Brasília, DF, abr.1999. Disponível em: <http://www.planalto.gov.br/ccivil 03/leis/L9795.htm>. Acesso em: dez. 2016.

BRASIL. Secretaria de Educação Fundamental. Parâmetros curriculares nacionais: introdução aos parâmetros curriculares nacionais / Secretaria de Educação Fundamental. - Brasília: MEC/SEF, 1997. 126p.

CAPELINI, M. Potencialidade e aplicação da prevenção de resíduos de embalagens: abordagem sobre o projeto do produto e o consumo. Tese (Doutorado) - Escola de Engenharia de São Carlos, Universidade de São Paulo, São Carlos. 2007. 273f.

CARVALHO, I.C.M. Educação Ambiental: a formação do sujeito ecológico. SP: 4a edição, Cortez, 2008.

COIMBRA, A. S. Interdisciplinaridade e Educação Ambiental: integrando seus princípios necessários. Disponível em: <http://www.ufjf.br/virtu/files/2010/03/artigo-1a2.pdf>. Acesso em: dez. 2016.

FRAGA, F. F. A expansão do turismo em São Miguel dos Milagres (AL): contribuições e obstáculos ao desenvolvimento local. Dissertação (Mestrado em Desenvolvimento e Meio Ambiente). Universidade Federal da Paraíba. João Pessoa, $2013 . \quad$ Disponível em: $<$ http://tede.biblioteca.ufpb.br/bitstream/tede/4544/1/arquivototal.pdf $>$. Acesso em: dez. 2016.

GIL, A. . Como elaborar projetos de pesquisa. 4. ed. São Paulo: Atlas, 2002.

LAYRARGUES, P.P. Educação Ambiental com compromisso social: o desafio da superação das desigualdades. In: LOUREIRO, C. F. B.; LAYRARGUES, P. P.; CASTRO, R.S. (Org.). Repensar a Educação Ambiental um olhar crítico. São Paulo: Cortez, p. 11-32, 2009.

QUINTAS, J.S. Educação no processo de gestão ambiental pública: a construção do ato pedagógico. In: LOUREIRO, C. F. B.; LAYRARGUES, P. P.; CASTRO, R.S. (Org.). Repensar a Educação Ambiental um olhar crítico. São Paulo: Cortez, p. 33-80, 2009.

SANTANA, G.R.A.; SANTOS, E.B. Conscientização ambiental da população na região central da APA Costa dos Corais. Revista Brasileira de Educação Ambiental (RevBEA), v. 11, n. 2, p. 118-126, 2016(a). 
SANTANA, G.R.A.; SANTOS, J.U. O protagonismo juvenil na conservação da área de proteção ambiental costa dos corais. Revista Brasileira de Educação Ambiental (RevBEA), V. 11, n. 1, p. 327-334, 2016(b).

SORRENTINO, M.; TRAJBER, R.; MENDONÇA, P.; FERRARO JUNIOR, L.A. Educação Ambiental como política pública. Educação e Pesquisa. São Paulo, v. 31, n. 2, pp. 285-299, 2005.

SOUZA, D. M. Os principais benefícios proporcionados ao trabalhador informal para formalização através do microempreendedor individual. Monografia (Curso de Ciências Contábeis). Universidade Federal de Santa Catarina. Florianópolis, 2010. $95 f$.

STEINER, A.Q.; AMARAL, F.M.D.; AMARAL, J.R.B.; SASSI, R.; BARRADAS, J.I. Zonação de recifes emersos da Área de Proteção Ambiental Costa dos Corais, Nordeste do Brasil. Iheringia, Sér. Zool. Vol.105 no.2 Porto Alegre June 2015. Disponível em: <http://dx.doi.org/10.1590/1678-476620151052184192>. Acesso em: dez. 2016. 